\title{
THE LIQUID WATER CONTENT OF SNOW MEASUREMENT IN THE FIELD
}

\author{
By I. G. Halliday \\ (Ministry of Supply, Royal Aircraft Establishment, Farnborough, England)
}

THIS note is a survey of the methods of measurement of water content of wet snow used by a number of observers. These are K. Croce ${ }^{1}$ of Inzell, Germany, formerly a member of the Inspectorate of German Roads, the late S. Sigurdsson ${ }^{2}$ of Reykjavik, Iceland, G. J. Klein ${ }^{3}$ of the National Research Council of Canada, Z. Yosida ${ }^{4}$ of Hokkaido University, Japan, Henri Bader ${ }^{5}$ of Rutgers University, New Jersey, U.S.A. and M. de Quervain ${ }^{6}$ of the Forschungsinstitut, Weissfluhjoch, Switzerland. With one or two exceptions each of these observers has approached the subject apparently with no knowledge of earlier work, no doubt due to the exceptional circumstances of recent years. This has resulted in considerable overlapping and makes a survey of their conclusions more difficult.

In the reports of these workers there is one main method, the calorimetric method, with which five of the reports deal, and a number of relatively unexplored methods.

\section{i. Calorimetric Method}

The main method used by Croce, Sigurdsson, Klein, Yosida and de Quervain is the most simple mode of procedure relying on the determination of the latent heat of the ice present in the ice-water mixture. A quantity of the wet snow is placed in a calorimeter containing hot water. The initial and final temperatures are observed. The computation of the results is simple and has been modified hardly at all by any of the observers, for, knowing the mass of snow and the water equivalent of the calorimeter and water, the mass of ice may be calculated from the temperature fall and the latent heat of melting of ice. Thus, if

$$
\begin{gathered}
m \text { is the mass of snow added } \\
X \quad, \quad \text {, ice in the wet snow } \\
\Delta T \quad \text { " temperature fall of the calorimeter } \\
T \quad \text { " final temperature } \\
M \quad \text { " mass of hot water in the calorimeter, and } \\
W \quad, \quad \text { water equivalent of the calorimeter }
\end{gathered}
$$

we have

$$
\begin{aligned}
m C T+X L & =(M+W) C \Delta T \\
X & =\frac{C}{L}[(M+W) \Delta T-m T]
\end{aligned}
$$

where $C$ is the specific heat of water in the temperature range considered and $L$ the latent heat of melting of ice.

This simple analysis, of course, has assumed that there is no heat loss from the calorimeter.

We shall be concerned then chiefly with the experimental details and the corrections applied for heat loss. Croce has made the most exhaustive examination of the method and because of this and the fact that his report contains most of the points considered in the other methods, his process will be dealt with in detail and the methods of the other observers mentioned only in so far as they differ from his.

For the vessel or calorimeter itself, Croce used a wide-necked vacuum flask in a wooden box with some sort of lagging between the flask and the box (see Fig. I, p. 358).* Its water equivalent

* This apparatus is also representative of most of the modifications discussed in this paper. It is taken from Croce's paper, page $\mathbf{r}_{5}$. 
was determined by a number of subsidiary experiments using dry snow. The temperature of the water in the calorimeter was measured with a thermometer reading to $0 \cdot I^{\circ} \mathrm{C}$. The sample of wet snow was extracted from the ground with a nickel-plated iron tube. Croce has made several suggestions for modifying this apparatus. $\mathrm{He}$ has built a calorimeter with a hole in the lid which can be covered by a slide which keeps the hot water hot, but which can be removed and a special sample holder put in its place. This holder contains a piston for forcing the sample into the calorimeter and another slide for retaining the sample before it is to be pushed into the calorimeter.The slide is removed, the sample pushed in, and the slide replaced to seal off the calorimeter. This arrangement lessens one of the greater sources of error, any loss in heat when the sample is inserted. As a later improvement he proposes also to use a heating coil to bring the calorimeter and melted sample back to the temperature of the original hot water. Knowing the amount of energy supplied a correction for the heat loss during the experiment can be made.

Croce made the weighings on a balance reading to one milligram. He suggests that instead of the mercury-in-glass thermometer a thermocouple might be used. The advantage of this suggestion seems doubtful for work in the field. An accurate calibration chart would have to be used to read to better than $0.1^{\circ} \mathrm{C}$. over an extended temperature range, and great care would be necessary not

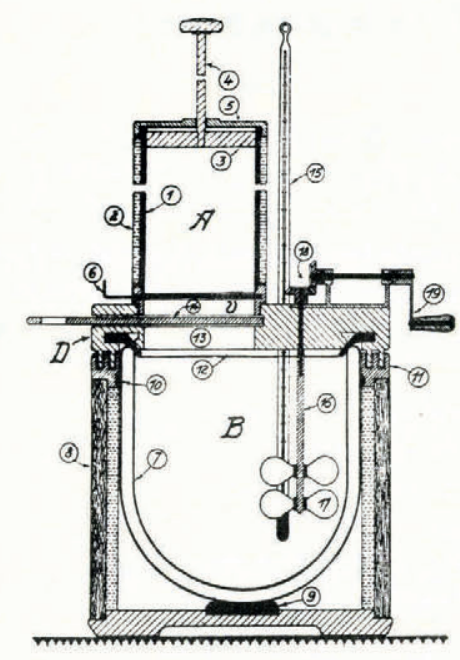

Fig. I. Diagram of a representative calorimeter possessing most of the modifications discussed in this paper. It is taken from Croce's paper, ${ }^{1}$ p. I5

to alter the calibration. Great accuracy can in fact be obtained by using electrical methods of temperature measurement, but only at the expense of considerable labour and experimental convenience.

Croce claims accuracy of 5 per cent of the water content. With his original apparatus this seems to the writer rather better than might be expected. With his newer apparatus the accuracy should be improved, perhaps by a factor of one half.

Sigurdsson's apparatus was considerably simpler than Croce's; he managed only to carry out a series of preliminary experiments. One improvement was to insert the sample with its holder into the calorimeter, thus avoiding heat losses and errors due to snow remaining in the holder.*

Sigurdsson used a brass calorimeter mounted in a brass box. He closed this with a rubber bung, avoiding the errors noted by Croce whose wooden lid tended to absorb water vapour.

* Mr. Robert Moss in an able preliminary review of these methods has suggested that if the sample holder be made of thin-walled tubing with large holes drilled in it, inspection of the sample for voids in the firn would enable density measurements of reasonable accuracy to be made. 
Klein used the most primitive calorimeter - a bucket. He states that he made no correction for heat loss nor for the thermal capacity of the bucket. He gives no estimate of his accuracy although he was able undoubtedly to work on a considerable scale.

Yosida's apparatus departs in a number of ways from Croce's. His calorimeter was of brass and his precautions against errors due to heat losses were rather in the form of a known compensation than an attempt at exclusion. The calorimeter was surrounded by a box, all walls of which, with the exception of the lid, were lagged with a water jacket. The temperature of the water was adjusted to be as close as possible to the expected final temperature. He observed the cooling curve of the calorimeter before the insertion of the sample and after the final equilibrium was reached. A correction for the heat loss in the dynamic cooling state could be made using Newton's Law of Cooling.

In his calculations Yosida took account of the variation of the specific heat of water with temperature. His systematic error, which included the water equivalent of the calorimeter, he determined as did Croce, by using a block of dry ice. He found this error to remain constant over a wide range of conditions. He estimated his experimental error to lie between 6 per cent for water contents around 5 per cent and 30 per cent for water content around I per cent.

De Quervain has discussed the limitations of accuracy involved in using hot water to melt the snow. He concludes that it is far better to use an electrical heating method. The advantages of this method will be discussed later.

De Quervain used a vacuum flask in a wooden box lagged with glass wool. Temperatures were determined with a mercury-in-glass thermometer though he suggests the use in future of thermocouples. He proposes to measure the electrical energy input calorimetrically, rather than by using a voltmeter and ammeter. No account is given of any experimental work in his report but de Quervain estimated his accuracy as being about $\pm I^{\prime} 5$ per cent of the water content.

\section{Alternative Methods}

A rather different approach to the direct calorimetric method is proposed by Bader. Instead of melting the ice by water he suggests that it be partially melted by the addition of an aqueous solution of some compound. The absorption of heat depresses the freezing point until phase equilibrium is reached. Either the depression in temperature or the concentration of the solution is measured, and with a knowledge of the various constants, the free water content of the snow can be calculated. It is not possible to compare these methods with the calorimetric method since Bader carried out no experimental study. The advantages at first sight seem useful. The usual corrections and precautions in accurate calorimetry are avoided since the temperature changes are less than one degree. This requires more accurate thermometry, however. Bader indicates that to obtain an accuracy of 1 per cent the temperature would have to be measured to a few hundredths of a degree. Such measurements in the field might prove difficult, but since the temperatures all lie between $\circ^{\circ} \mathrm{C}$. and $-\mathrm{r}^{\circ} \mathrm{C}$., some thermometer of the Beckmann type could be used with a minimum of the trouble usually associated with such instruments. If instead of the temperature depression the concentration is to be measured, titration may be possible in the field. Bader suggests as an eminently feasible method for laboratory use a solution of an optically active compound where accurate polarimetric measurements could speedily indicate composition changes. The gain in accuracy appears considerable, for, using a saccharimeter reading to $0^{\circ} \mathrm{O}^{\circ}$, an accuracy of better than 0.5 per cent could be attained, which must certainly be greater than the sampling errors. Too little is reported by Bader, however, to decide whether the difficulties in procedure would outweigh the advantages in accuracy.

Yosida suggests that the change in volume of the ice on melting could provide a parameter for measurement. He points out the obvious difficulties due to dead space, which may be difficult to avoid in such a method. 
No mention appears to have been made of the use of "chemical" methods where the water is washed out of the ice crystals by a non-miscible liquid and determined directly by volume after filtration. Such methods might merit consideration.

\section{Comparison of the Results of Croce, Sigurdsson and Yosida}

An attempt will now be made to tabulate the values of the quantities involved in the measurement of the three observers Croce, Sigurdsson and Yosida.

\begin{tabular}{|c|c|c|c|c|c|}
\hline & $\begin{array}{c}\text { Thermometer } \\
\text { reading to }\end{array}$ & $\begin{array}{l}\text { Weight of } \\
\text { water used }\end{array}$ & $\begin{array}{c}\text { Temperaizre } \\
\text { of water }\end{array}$ & $\begin{array}{c}\text { Final } \\
\text { temperature }\end{array}$ & $\begin{array}{c}\text { Accuracy (\% } \\
\text { water content) }\end{array}$ \\
\hline Croce & ${ }^{\circ} \mathrm{C}$. & $500-600 \mathrm{~g}$ & ${ }_{50-70}^{\circ} \mathrm{C}$. & ${ }^{\circ} \mathrm{C}$. & \pm 5 \\
\hline Sigurdsson & 0.5 & $\frac{\text { Wt. of water }}{\text { Wt. of sample }}=3$ & - & - & $6(?)$ \\
\hline Yosida & 0.1 & $150 \mathrm{~g}$. & 30 & 10 & $6-30$ \\
\hline
\end{tabular}

Croce's estimate of his accuracy appears reliable, as does Yosida's. Sigurdsson, using few of the refinements of the other two, can hardly have had the same accuracy. The figure of 6 per cent which he gives as an estimate is not based on experiment.

A criterion for the accuracy of the calorimetric method is provided by the quantity $\Delta T_{E}$, the temperature rise of the sample per cent water content. The theoretical maximum can easily be calculated to be about 0.5 degrees per cent of water content. To approach this a very small amount of very hot water should be used, but this, however, increases the heat loss errors. Some compromise is necessary and an experimental modification which either reduces or measures the heat loss, whilst allowing the value of $\Delta T_{E}$ to approach its maximum, is the most desirable. Of the "water" methods, Yosida's would seem most satisfactorily to possess this possibility. Using his lagging and Croce's double chamber a value of $\Delta T_{E}$ of about 0.4 degrees per cent of water content should be possible.

In his latest report Croce suggests that instead of using hot water to melt the snow, an electric heating coil should be used. This has the advantage that $\Delta T_{E}$ can become its theoretical maximum. No heat loss should be experienced, since if the surroundings are at $0^{\circ} \mathrm{C}$., and if slow rates of heating are used to ensure only small local rises in temperature, the temperature of the calorimeter is never above that of its surroundings. The thermometer need only be used to determine when all the snow is melted; here thermocouples could be used to great advantage. Croce seems to distrust voltmeters and ammeters for power measurements, preferring wattmeters or a calorimetric method.

The author finds it difficult to understand why any other method has been used. It should be quite simple to obtain an accuracy of I per cent. All the extra apparatus needed is a small battery weighing perhaps $4 \mathrm{~kg}$. or less and a voltmeter and an ammeter. There are no evaporation losses. The sample cutter could serve as the calorimeter. No lagging is necessary if there are no cold draughts. However, no doubt the relative weights of the equipment required by the different methods is not without influence on the final selection of a field method.

This method and Bader's methods seem in the writer's opinion to hold the most promise.

The author would like to take the opportunity of thanking Mr. Robert Moss for the use of his translation of Croce's papers and his amended English version of Sigurdsson's paper; also to acknowledge a number of suggestions and comments by Mr. Moss made in private communications. $M S$. received 22 fuly 1949 


\section{R E F E R E N C E S}

1. Croce, K. Bestimmung der Schneefeuchtigkeit. Arbeitsbericht A.x. der Schneeforschungsstelle des Generalinspektors für das deutsche Strassenwesen (München), 1943. 33 pages, diagrams, ills. (Privately circulated and amended in a further privately circulated communication of 1948.$)^{*}$

2. Sigurdsson, S. Private communication.*

3. Klein, G. J. Canadian survey of physical characteristics of snow covers. National Research Council of Canada, Division of Mechanical Engineering, Ottawa, 1948. Communication to the International Union of Geodesy and Geophysics, Oslo, 1948, 17 pages, diagrams, ills.

4. Yosida, Zyungo. A method of determining the thaw water content in snow layer. Investigations on Snow, No. 14 , Fournal of the Faculty of Science, Hokkaido University, Series 2, Vol. 3, No. 4, 1940, p. 91-102.

5. Bader, Henri. Theory of non-calorimetric methods for the determination of the liquid water content of wet snow: Schweizerische Mineralogische und Petrographische Mitteilungen, Vol. 28, 1948, p. 355-6I.

6. Quervain, M. de. Private communication.*

* Manuscripts in the possession of the Society.

\section{INSTRUMENTS AND METHODS}

\section{IMPROVEMENT IN MAKING RUBBINGS OF \\ GLACIER CRYSTALS}

THE method of making rubbings with a pencil described in my paper (Fournal of Glaciology, Vol. I, No. 5, p. 255) has been found unsuitable when the ice is very wet. Professor Ahlmann overcame this difficulty by the "printing" method described on page 269 of the same issue, but I think it will be found that pencil rubbings are simpler and quicker. The following notes should overcome the difficulties experienced with pencil rubbings on wet ice.

Recent experiment has shown that it is better not to use "slightly absorbent" paper as formerly recommended. If the paper absorbs too much water the pencil will not mark. Non-absorbent paper must nevertheless be fairly soft but not nearly so thin as the towelling used by Professor Ahlmann.

When the ice is very wet the paper should not be placed flat on the ice but should be rolled up into a loose roll. Assuming the pencil to be held in the right hand, place the roll on the righthand edge of the ice to be rubbed. Commence rubbing up and down this edge. As the pencil progresses leftwards it uncurls and flattens more and more of the roll. Thus the strip of paper immediately beneath the pencil only comes in contact with the ice at the moment the pencil is marking it. It therefore does not become wet through until after the pencil has passed by. The rubbings in Figs. 3 and 4 (p. 378) were made by this method on very wet ice.

"Heel ball," a black stick of solid dye as used by bootmakers to blacken shoes, sometimes works better than a pencil.

G. Seligman 